article "The Forest as a Factory" (NATURE, February 26, p. 243). In spite of the handicaps of loss of manpower and shortages of plant and equipment, the saw milling industry of Australia rose to the emergency and increased production to a peak which fulfilled all demands at the time. Latterly, however, there has been a serious decline owing to lack of labour, trucks, tractors, spare parts and so forth-rather like the position of farming and its mechanization, in some parts at least, of Britain. It is not surprising to read that some States in Australia which were previously exporters are now importers, and that the timber control authorities have had to reorientate the flow and usage of timber. Civilian demands are treated very much as in Great Britain, and plywood is said to be already unprocurable. It is difficult to foresee what will be the ultimate demands upon the forests of the country, but it appears certain that a careful consideration of a future forest policy for the continent as a whole will be essential, if the country is not to be faced with the twin evils of increasing aridity and depreciation of water supplies, the usual aftermath of excessive and hurried forest fellings, no matter how justified these may be at the present time.

That the possible post-war needs are realized is indicated by the following quotation: "Timber, the raw material for such a widespread national industry as sawmilling, as well as paper and pulpwood manufacture, plywood and wall board fabrication, etc., can only be obtained in continuing supply under a wellplanned and uninterrupted forest policy". The value of a long-term planting scheme is demonstrated by the exotic pine forests in the south-east of South Australia, from which $40,000,000$ super feet of softwood are now being cut annually where originally there was only inferior hardwood forests of very limited extent. "The establishment of plantations and the successful regeneration of heavily-cut forests will require the skill and experience of trained foresters in greater numbers than are available to-day. For this reason alone there is a necessity to initiate the immediate training and education of men who can be called upon later for this work. State authorities would help the post-war problem considerably by giving urgent attention to this most important question. In some cases this will involve, as in the case of other professional training, a temporary loss of services to the armed Forces, which, however, must themselves benefit from this very training." Both New Zealand and Australia have recognized the wisdom of this latter step; the Ministry of Labour and National Service in Great Britain has so far found it difficult to appreciate this aspect of the problem.

\section{The Planetary Companion of 61 Cygril}

Dr. Robert AITKEN has given a short account of the new companion to 61 Cygni, which has aroused considerable interest because of its planetary nature (Astro. Soc. Pacific, Leaf. 177; 1943). In 1914, Hertzsprung perfected a photographic method for measuring the motion in double stars, and this method gave results of much higher accuraey than those obtained by other means. It is considered that the photographic measurements made by this method by Hertzsprung with the long-focus telescopes at Potsdam and at the Lick Observatory, and by Strand at the Sproul Observatory, are the most accurate double-star measures that have been made. When Strand plotted the measures of the two bright components of 61 Cygni, from 1914 on, he found that the curve of their relative motion was not a perfectly smooth ellipse, but a wavy line, and this wave motion could even be traced backwards from 1914 by the use of plates taken by Lewis M. Rutherford by the old wet-plate process.

There is now no doubt about the existence of the third small body, which revolves with one of the bright stars in a period of 4.9 years. The mass of 61 Cygni $C$, the name given to this small body, is about ten times that of Jupiter, and it is very doubtful whether it is permissible to extrapolate the stellar relationships between mass, temperature, luminosity and density, to such a relatively small body, which cannot be considered a normal star. Prof. H. N. Russell states (Astro. Soc. Pacific, Leaf. 170; April 1943) that we are dealing with a borderline body, and discusses a number of problems that arise in connexion with such a unique discovery. There is no reason why many other similar bodies should not exist, but those that are far removed from us would be difficult to discover.

\section{Shasta Dam}

THE possible effect of earthquakes has been taken into account in the building of the Shasta Dam (Earthquake Notes, Eastern Section, Seismological Society of America, 15, Nos. 1 and 2, Sept. 1943, p. 4). An analysis was first made, according to Kenneth $B$. Keener, of the conditions existing both when the reservoir is full and when it is empty, each with and without earthquake effects, and in view of this analysis certain assumptions were made. These assumptions were then taken into account when designing the structure of the dam. The assumptions were : (1) the uplift pressure is not affected by the earthquake shock; (2) the horizontal and vertical components of an assumed earthquake shock have an acceleration equal to one tenth gravity, and a vibration period of one second; (3) the horizontal component has a direction of vibration normal to the axis of the dam.

\section{Bibliography of Seismology}

THE Bibliography of Seismology, published at the Dominion Observatory at Ottawa and compiled by Ernest A. Hodgson (13, No. 13, items 5440-5563. January to June 1943), has just been received. It contains items of interest to seismologists from almost pure geology, physics, chemistry and applied mathematics through pure seismology to notices of seismic patents for prospecting. Several items have already been noticed in the columns of NATURE. Interesting applications of seismology occur in items 5,480 and 5,500. The former concerns "Instruments for Measuring Vibrations in Grand Coulee Dam" and refers to Engineering News Record, 129, 64 (New York, Dec. 31, 1942). The latter, by Ernest A. Hodgson, refers to "Rockburst Research in Lake Shore Mines" and is to be found in Miner and Mine, 1, No. 1, 4-5, Kirkland Lake, March 1943. Item 5562 refers to a most careful piece of work by Harry O. Wood, "Earthquakes and Disturbances to Leveling in the Imperial Valley", and is taken from Bulletin of the Seismological Society of America, 32, No. 4, 257-268 (Berkeley, Oct. 1942). The United States Coast and Geodetic Survey surveyed the area by precise levelling in 1926-27, 1928 and 1931, and sent a field investigation unit to the Imperial Valley, California, in 1930, after the earthquakes of February 25 and March 1, 1930. The author's opinion of the probable cause of the change in levels between 1927-28 